American Journal of Pharmaceutical Education 2019; 83 (6) Article 6842.

\title{
RESEARCH
}

\section{Design and Evaluation of a Professional Identity Development Program for Pharmacy Students}

\author{
Martina F. Mylrea, PhD, Tarun Sen Gupta, PhD, Beverley D. Glass, PhD \\ James Cook University, College of Medicine and Dentistry, Queensland, Australia \\ Submitted October 10, 2017; accepted March 5, 2018; published August 2019.
}

Objective. To design and evaluate a professional identity program (PIP) based on self-determination theory (SDT) for entering Bachelor of Pharmacy (BPharm) students.

Methods. The PIP, which featured autonomy-supportive teaching approaches, was delivered as 10 workshops that were integrated into existing pharmacy courses over the first four semesters (2 years) of the BPharm program. The program was evaluated using a student satisfaction survey and two previously validated tools for measuring professional identity (MCPIS-9) and motivation to study pharmacy (Pharm-S). Nonparametric statistical techniques were used to compare students' scores before and after introducing the PIP.

Results. Students responded positively to the introduction of the PIP in the pharmacy program. Based on survey responses, the students valued opportunities to engage in activities and discussions related to professional development and identity formation. Student scores on the motivation-based tool (PharmS) increased by the end of the first year of participation in the PIP, indicating an increase in student autonomy levels. There was no change in students' scores on the professional identity measure (MCPIS-9) after the first year.

Conclusion. The use of SDT-based instruction in professional identity education resulted in increased levels of autonomy in pharmacy students, indicating a transition to more intrinsic levels of motivation. This has the potential to positively impact student professional identity and future professional practice.

Keywords: professional identity, self-determination theory, pharmacy education, health professionals, motivation

\section{INTRODUCTION}

Personal and professional development is an educational outcome essential to the contemporary practice of pharmacy as outlined in Standards 2016, ${ }^{1}$ published by the Accreditation Council for Pharmacy Education (ACPE). Standard 4 requires that students acquire core knowledge and skills, as well as attitudes, values, and behaviors that exemplify the practice of pharmacy. The ability to demonstrate professionalism is identified as fundamental, this being predicated by the capacity for selfawareness as a mechanism to promote professional growth. ${ }^{1}$ Cruess and colleagues concluded that the basis of student professionalism should be the development of professional identity. ${ }^{2}$ In 2014 a professional identity for-

Corresponding Author: Martina F. Mylrea, School of Pharmacy, College of Medicine and Dentistry, James Cook University, Townsville, Queensland, Australia 4811. Tel: +61 74781 6803. Fax: +61 74725 8108. E-mail: martina.mylrea@jcu.edu.au mation (PIF) task force was established by the American Association of Colleges of Pharmacy Council of Deans (AACP-COD). ${ }^{3}$ The task force released a report that defined PIF as being "the transformative process of identifying and internalizing the ways of being and relating within a professional role." The report also made recommendations for best practices in the development of pharmacy student professional identity, which involved creating opportunities within and beyond the established curriculum.

Jarvis-Selinger and colleagues ${ }^{4}$ explain that identity is formed at both the individual (psychological) and collective levels where the person is socialized into roles and relationships in the work setting. Of particular relevance to this study is the observation by Skorikov and Vondracek who state that that human motivation also has a role to play in the formation of professional identity. They state that professional identity is a "complex structure of meanings in which the individual links his or her motivation and competencies with acceptable career roles." ${ }^{\circ}$ Research 


\section{American Journal of Pharmaceutical Education 2019; 83 (6) Article 6842.}

into the development of professional identity in pharmacy students has largely focused on the collective level, as it reports on the importance of role models, interactions with practicing professionals, and experiential education. ${ }^{6-8}$ However, Dall'Alba ${ }^{9}$ highlights the importance of the individual level in the development of professional identity and describes the importance of developing a sense of who the student is becoming through an ontological as well as epistemological approach to teaching aspiring professionals. Such an approach would mean creating opportunities for students to think, act, and feel like a professional. ${ }^{2,9}$

There is limited research on pedagogical approaches to PIF in pharmacy education. ${ }^{10,11}$ There is agreement among medical, pharmacy, and nursing education that concepts around professionalism and professional identity should be introduced in the early stages of a program of study. ${ }^{11-13}$ Van Huyssteen and Bheekie ${ }^{14}$ used the medium of reflective writing to develop professional identity in first-year pharmacy students, resulting in them having an improved sense of belonging to the pharmacy profession. Johnson and Chauvin ${ }^{10}$ concluded that the deliberate structuring of learning opportunities can promote PIF. Noble and colleagues state that there are many opportunities within the pharmacy curriculum for PIF, identifying it as a significant factor in the successful transition of graduates from the university to the workplace. ${ }^{11}$ As Adams and colleagues ${ }^{15}$ observe, the challenge is to create or find a framework that will develop an understanding of what it means to be a practicing professional, and to design educational programs that prepare aspiring professionals for the challenges of professional practice.

There is therefore a need to investigate a theoretical approach to developing individual professional identity in pharmacy students. ${ }^{16}$ Research with a focus on pedagogies that support the individual (psychological) level is lacking; therefore, a framework that is informed by an understanding of the mechanisms behind individual identity development is needed. ${ }^{16}$ To address this issue, Mylrea and colleagues ${ }^{17}$ proposed Deci and Ryan's ${ }^{18,19}$ self-determination theory (SDT) as a relevant framework upon which to base pedagogical approaches to PIF.

Self-determination theory explains identity formation as a function of self-motivation (motivation may be absent, externally or intrinsically driven). In this model, identity is formed through the process of internalization, occurring as the values and culture of an activity are integrated, to become part of one's self (Figure 1). The highly regarded theory states that an intrinsically motivated individual will exhibit highly self-directed (autonomous) behaviors as the activity or pursuit becomes part of their individual identity. ${ }^{20,21}$ Self-determination theory

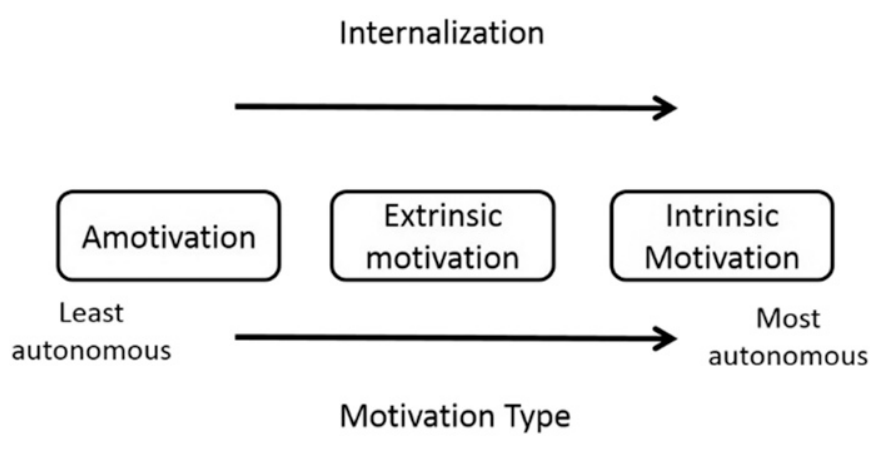

Figure 1. Diagrammatic Representation of Motivation Types as Described by Self-Determination Theory. Adapted from Ryan and Deci ${ }^{19}$

states that an individual will internalize a role or activity and form an identity if the student is supported in three basic psychological needs: competence, relatedness, and autonomy.

The purpose of this study was to design a professional identity program (PIP) that would facilitate the formation of professional identity in pharmacy students, using SDT to underpin instructional design. ${ }^{17}$ The program employed autonomy-supportive teaching ${ }^{22}$ techniques and was designed to provide students in their first year of study with the opportunity to begin to think, act, and feel like a pharmacist. This study also evaluated the PIP and tested the hypothesis that the introduction of the PIP across the first two years of a pharmacy program would increase student professional identity and autonomy.

\section{METHODS}

In Australia, after completion of a four-year Bachelor of Pharmacy (BPharm) program and a one-year internship, graduates can register as pharmacists. To address the early professional development of pharmacy students, this study focused on students as they entered their first year and progressed through their second year of the BPharm program at James Cook University (JCU). The program has a modern, integrated curriculum in which body systems, associated disease states, and relevant therapeutics are taught concurrently, providing learners with opportunities to make meaningful connections between the scientific basis of therapeutics and the practice of pharmacy. Students in their first year of study undertake a combination of science-based subjects (eg, biochemistry) and pharmacy-specific subjects, the latter designed to introduce students to the professional aspects of pharmacy practice. Approval for the study was sought and granted from the JCU Human Ethics Committee.

An SDT-based professional identity program (PIP) was designed for pharmacy students in their first and 


\section{American Journal of Pharmaceutical Education 2019; 83 (6) Article 6842.}

second year of the BPharm program. Workshop sessions were developed with the aim of supporting student competence, relatedness, and autonomy, and integrated into the compulsory, pharmacy-specific courses each semester for the first two years of study. Strategies for supporting these three psychological needs were adapted from work by Kusurkar and colleagues ${ }^{22}$ who previously applied SDT to medical education, an approach later formalized by Orsini and colleagues ${ }^{23}$ (Table 1).

The PIP was conducted from the beginning of semester 1, 2015 (February), to the end of semester 2, 2016 (December) (four, 13-week semesters in total). As students do not embark on their first professional placement until their third year of study, this program was designed to provide early opportunities for students to be exposed to and engage with aspects of the profession of pharmacy while building competence, relatedness, and autonomy. Building on previous research on professional development, ${ }^{6,7}$ the PIP consisted of 10 workshops that featured interaction with practicing pharmacists, group discussions, reflective writing, and practice-related activities such as compounding and counseling (Table 2).

The first PIP workshop began with group discussions on professionalism and professional identity and encouraged student participation and input. The intention was to initiate an early dialogue with students around the very attributes that would define their daily professional activities. Workshop 2 was dedicated to the concept of pharmacist identities, based on recent research by Elvey and colleagues, ${ }^{24}$ and used an interactive group activity to explore the multiple roles of the pharmacist. The program was delivered using autonomy-supportive teaching techniques, ${ }^{22}$ and as indicated in the CAPE educational outcomes, also incorporated a reflective activity and selfawareness training. As the role of reflective activities in professional development is well documented, ${ }^{25-27}$ students were given a suite of suggested topics or a self- nominated topic and asked to reflect on their professional development over the course of the first 13-week semester (workshop 7). Student reflections were created and submitted using an online e-portfolio system, PebblePad ${ }^{+}$ (Pebble Learning, University of Wolverhampton, UK) in the form of an online blog. The students received individual feedback on their blog entries via ATLAS, which is the assessment portal in PebblePad ${ }^{+}$. In the final workshop, students' self-awareness was increased through participation in rudimentary emotional intelligence (EI) training, with a specific focus on the role of EI in the pharmacy workplace.

First-year BPharm students were given a brief presentation about the study, during which they were provided with an information sheet that outlined the objectives of the study. Students were informed that the PIP would be integrated into their existing curriculum and that they would be surveyed at regular intervals during the program.

Two measures were used to evaluate the program: a paper-based student satisfaction survey designed to evaluate student perceptions of the PIP, administered 12 months after the PIP began, and an online professional identity survey incorporating two previously validated professional identity/motivation tools (MCPIS- $9^{28}$ and the Pharm- $\mathrm{S}^{29}$ ). The MCPIS-9 is a professional identity instrument validated by Worthington and colleagues. ${ }^{28}$ The instrument consists of 9-items, which asked the students to indicate how connected they felt to the pharmacy profession. Students were asked to indicate their level of agreement with statements such as, "Being a member of the pharmacy profession is important to me," using a fivepoint Likert-type scale $(1=$ strongly disagree and $5=$ strongly agree). The second tool used was the Pharm-S, ${ }^{29}$ a previously validated, 14-item tool based on SDT that was created by Mylrea and colleagues. ${ }^{29}$ Adapted from a sports motivation scale, the Pharm-S is designed to assess motivation regulators as they relate

Table 1. Strategies for Supporting Basic Psychological Needs ${ }^{\mathrm{a}}$ Used in the Professional Identity Program Workshops ${ }^{\mathrm{b}}$

\begin{tabular}{llll}
\hline Need & \multicolumn{1}{c}{ Competence } & Relatedness & \multicolumn{1}{c}{ Autonomy } \\
\hline Strategies & Provide optimal challenges & Respect students & Identify what students want \\
& Provide structured guidance & Give emotional support & Provide different learning approaches \\
& Value students work & Acknowledge students' & Give value to uninteresting tasks \\
& Give positive and constructive & expressions of negative effect & Promote active participation \\
& feedback & & Give choice \\
& & & Give learning responsibility \\
& & & Provide freedom \\
& & Avoid external reward \\
\hline
\end{tabular}

${ }^{a}$ Identified by Orsini and colleagues ${ }^{23}$

${ }^{\mathrm{b}}$ Reproduced with permission under the terms of the Creative Commons Attribution License 


\section{American Journal of Pharmaceutical Education 2019; 83 (6) Article 6842.}

Table 2. Professional Identity Program Workshops Integrated Into a Bachelor of Pharmacy Curriculum

\begin{tabular}{|c|c|c|c|}
\hline \multicolumn{2}{|c|}{ Workshop } & \multirow{2}{*}{$\begin{array}{l}\text { Title } \\
\text { Introduction: Professionalism and } \\
\text { professional identity }\end{array}$} & \multirow{2}{*}{$\begin{array}{l}\text { Description } \\
\text { Definitions of professionalism USA, Australia } \\
\text { Code of Ethics 2011, Code of Conduct } 2014\end{array}$} \\
\hline 1 & L1:Sem 1 & & \\
\hline 3 & L1:Sem 1 & Professional identity development & Group discussions: The rural pharmacist \\
\hline 4 & L1:Sem 2 & Exploring the role of the pharmacist & $\begin{array}{l}\text { The counsellor: Video analysis } \\
\text { The medicine maker: Compounding activity }\end{array}$ \\
\hline 7 & L2:Sem1 & My professional identity & Extended reflective activity: PebblePad + platform \\
\hline 8 & L2:Sem1 & Compounding group project & Compounding scenario activity $(2 \times 3 \mathrm{hrs})$ \\
\hline $9-10$ & L2:Sem2 & Emotional intelligence training & Group activities and discussion $(2 \times 2 \mathrm{hrs})$ \\
\hline
\end{tabular}

$\mathrm{L} 1=$ First year, $\mathrm{L} 2=$ Second year, Sem $=$ Semester (The BPharm consists of two semesters per calendar year)

to what drives students to pursue the profession of pharmacy. Details of the design and validation of the Pharm-S can be found in an earlier paper. ${ }^{29}$ Responses on the Pharm-S were recorded on a five-point Likert-type scale $(1=$ does not correspond at all, $5=$ completely corresponds). Questions that related to demographic aspects of the participants were also included on the survey instrument.

The professional identity survey was first administered to entering BPharm students in 2014. These students did not receive professional identity instruction as part of the curriculum. They were surveyed using the same survey instrument at 0,12 , and 24 months to provide comparative data. They are referred to in the study as "non-PIP" students. Their responses were used for comparison with those of students in the study group. The study group was the group of students who enrolled in 2015 and participated in the PIP for the following two years. These students also were surveyed at 0,12 and 24 months using the same survey instrument.

Responses on all administrations of the professional identity survey were collated and summarized. Response rates were calculated as a percentage of the total number of students in the relevant cohort. An arithmetic mean was calculated for the MCPIS-9 items. Scores on the Pharm-S items were aggregated according to a weighted formula as prescribed by the Relative Autonomy Index (RAI). ${ }^{30}$

Participation in the survey was voluntary and students' anonymity was assured. The survey was administered using SurveyMonkey (SurveyMonkey, Palo Alto, $\mathrm{CA})$ with consent to participate built into the online introduction to the survey instrument.

Data analysis was completed using Statistical Package for the Social Sciences software, Version 23.0 (SPSS Inc, Chicago, IL). Descriptive statistical techniques were used to analyze demographic data. The Kolmogorov-
Smirnov test confirmed that the data were not normally distributed, so nonparametric analysis was undertaken. Group differences were therefore explored using the Wilcoxon signed-rank test for pre and post PIP scores, and Mann-Whitney U tests were used to compare the unrelated groups. A level of $\alpha=.05$ was used to determine significance. Data were also screened for outliers and missing values.

\section{RESULTS}

The program evaluation survey asked the students to respond to questions relating to the content and delivery of the PIP. There were 44 respondents $(88 \%$ response rate), of which 18 were male and 26 were female, with a mean age of 20 years $(\mathrm{SD}=4.2$ years; range $=17-35$ years). One hundred percent of the respondents felt that they gained a greater understanding of the importance of professionalism through participation in the PIP, $91 \%$ felt that they had a greater understanding of the role of the pharmacist, and $84 \%$ felt that the PI sessions improved their sense of professional identity.

The professional identity survey consisted of a series of demographic questions in addition to items from the MCPIS- $9^{28}$ and the Pharm-S. ${ }^{29}$ Demographic results for the control and study groups (2014 and 2015) are summarized in Table 3, and scores for both groups on the identity and motivation tools are summarized in Table 4.

The data in Table 3 represent two successive years (2014 and 2015) of pharmacy students enrolled in the first year of the BPharm program. The students enrolled in 2015 participated in the PIP for the following two years, while the students enrolled in 2014 did not participate in the PIP (non-PIP). The responses of the non-PIP group were used as a type of control group for comparison purposes. Response rates for this survey were $72 \%$ for 2014 and $88 \%$ for 2015 . The data show a disproportionate number of female students in the 2014 group of respondents, 


\section{American Journal of Pharmaceutical Education 2019; 83 (6) Article 6842.}

Table 3. Participant Demographic Characteristics and Response Rates of the First Year BPharm Cohort in 2014 and 2015

\begin{tabular}{|c|c|c|}
\hline Characteristic & $\begin{array}{c}\text { First year intake } \\
(\mathbf{2 0 1 4 )}\end{array}$ & $\begin{array}{l}\text { First year intake } \\
(2015) \\
\end{array}$ \\
\hline Age, mean (SD) yrs & $20.1(5.5)$ & $20.0(5.8)$ \\
\hline Sex: female, $\%$ & 87.5 & 55.3 \\
\hline Pharmacy was the course of first choice: yes, $\%$ & 60 & 62 \\
\hline Worked or works in practice: yes, $\%$ & 32.5 & 21.3 \\
\hline Percentage Response rates (\%) & 61 & 51 \\
\hline
\end{tabular}

which reflects the higher proportion of female students enrolled in $2014(72 \%)$.

For the 2014 (non-PIP) and 2015 (PIP) cohorts, the professional identity survey was administered at 0,12 , and 24 months after enrolment in the BPharm program. Students entering the course $($ Time $=0)$ scored highly on the MCPIS-9 items, with an average score of 4.1 (Table 4). Furthermore, the MCPIS-9 scores for both PIP participants and non-participants did not significantly change across the two-year testing period.

The Pharm-S scores for those students who had received (PIP) and not received the PIP (non-PIP) were also compared using the Mann-Whitney $\mathrm{U}$ test. This analysis revealed that after 24 months the students who participated in the PIP scored significantly higher on the Pharm-S items than students who did not participate in the PIP ( $\mathrm{U}=421, \mathrm{Z}=-2.5, p=.012)$ (Table 4).

The Wilcoxon signed-rank test was used to determine if there were any changes in Pharm-S scores among the student group who received the PIP (Table 5). No significant differences were detected in the survey scores after the first year of the study $(T=0$ to $T=12)$. However, a significant increase in Pharm-S scores occurred between the 12-month and 24-month mark after commencement of the PIP. Analysis revealed that the median posttest ranks, $(\mathrm{Mdn}=12.8$ $[\mathrm{T}=24])$, were significantly higher than the median pretest ranks $(\mathrm{Mdn}=9.0[\mathrm{~T}=12], \mathrm{Z}=-2.3, p=.02)$ (Table 5).
A breakdown of the overall Pharm-S score into the three motivation types discussed earlier (ie, amotivation, extrinsic motivation, and intrinsic motivation) revealed changes consistent with increasing levels of autonomy across the two years in which the PIP was conducted. A visual representation of this breakdown is shown in Figure 2. This reveals a drop in amotivation scores (indicating a reduction in the occurrence of amotivation) and an increase in the scores associated with both extrinsic and intrinsic motivation type. There was a statistically significant increase in scores for intrinsic motivation between 12 and 24 months, $(Z=-3.3, p=.001)$, with similar increases occurring for extrinsic motivation $(Z=-2.1$, $p=.03)$.

\section{DISCUSSION}

First-year pharmacy students participating in a professional identity program during the first 24 months of their study program reacted positively to its early inclusion in the BPharm degree. The majority of students welcomed the opportunity to discuss the professional practice of pharmacy as part of their studies and felt that the program increased their understanding of professionalism and professional identity. Encouraging early discussion about the role of the pharmacist as a strategy for facilitating development of students' professional identities has been recommended. ${ }^{11}$

Table 4. MCPIS-9 and Pharm-S Scores for Participating and Non-participating Students in the Professional Identity Program (PIP) Over Two Years

\begin{tabular}{|c|c|c|c|c|c|c|c|c|}
\hline \multirow{3}{*}{$\begin{array}{l}\text { Time } \\
\text { (months) }\end{array}$} & \multicolumn{2}{|c|}{ Response Rates $^{\mathrm{a}}$} & \multirow{2}{*}{\multicolumn{2}{|c|}{ MCPIS-9 ${ }^{b}$ Mean (SD) }} & \multirow{3}{*}{$\begin{array}{c}p \text { value } \\
\text { PIP vs } \\
\text { Non-PIP }\end{array}$} & \multirow{2}{*}{\multicolumn{2}{|c|}{ Pharm-S $^{\text {c }}$ Mean (SD) }} & \multirow{3}{*}{$\begin{array}{c}p \text { value } \\
\text { PIP vs } \\
\text { Non-PIP }\end{array}$} \\
\hline & \multirow{2}{*}{$\begin{array}{c}\text { PIP } \\
\text { n (\%) }\end{array}$} & \multirow{2}{*}{$\begin{array}{c}\text { Non-PIP } \\
\text { n }(\%)\end{array}$} & & & & & & \\
\hline & & & PIP & Non-PIP & & PIP & Non-PIP & \\
\hline 12 & $48(94)$ & $33(57)$ & $4.0(0.63)$ & $4.1(0.64)$ & .68 & $9.0(6.7)$ & $9.0(5.6)$ & .93 \\
\hline
\end{tabular}

Significance was determined by the Mann-Whitney U test

${ }^{a}$ Survey participation was voluntary so response rates (in parenthesis) varied at each time interval

${ }^{\mathrm{b}}$ MCPIS-9 (MacLeod Clark Professional Identity Scale) ${ }^{28}$

${ }^{c}$ Pharm-S ${ }^{29}$ (Pharmacy Motivation Scale) scores aggregated using a weighted average as prescribed by the Relative Autonomy Index (RAI) ${ }^{30}$ 


\section{American Journal of Pharmaceutical Education 2019; 83 (6) Article 6842.}

Table 5. Statistically Significant Differences in Student Pharm-S Scores Across Two Years in the Professional Identity Program (PIP)

\begin{tabular}{lcc}
\hline Time, months & $\begin{array}{c}\text { Pharm-S } \\
\text { Mean (SD) }\end{array}$ & $\boldsymbol{p}$ Value \\
\hline 0 & $10.2(5.1)$ & .06 \\
12 & $9.0(6.7)$ & .02 \\
24 & $12.2(4.7)$ & \\
\hline
\end{tabular}

Significance was determined by the Wilcoxon signed-rank test

${ }^{\text {a }}$ Scores on the Pharm-S were aggregated using a weighted average as prescribed by the Relative Autonomy Index (RAI) ${ }^{30}$

${ }^{\mathrm{b}}$ Significance level, two-tailed, $<.05$

We evaluated the effect of the program on the professional identity and motivation of the participating students. Two validated survey instruments were used to detect changes in student professional identity and motivation types over a two-year period. Data from the MCPIS-9 revealed high levels of perceived professional identity at the beginning of the study, with no significant change in the scores during the two years of the study, irrespective of whether the students received the professional identity training or not. In their study, which also used the MCPIS-9 measure, Adams and colleagues reported similar findings for 10 different health professions, including pharmacy. ${ }^{31}$ The authors suggest that strong professional identity in new students is a result of their acceptance and subsequent enrollment in the course. The MCPIS-9 is a single factor instrument, designed to explore whether participants positively identify with the profession, in this case pharmacy. ${ }^{28}$ However, the narrow scope of this instrument does not provide insight into the development of professional identity in students, an aspect which the Pharm-S does assess.

The Pharm-S tool examined motivation types as they related to the profession of pharmacy. After 24 months of participation in the PIP, students' Pharm-S scores increased significantly. This suggests that during their second year of study, students' levels of autonomy (selfdetermination) associated with the profession of pharmacy increased compared to that of students who did not participate in the program (non-PIP). This illustrates the longterm approach required for professional development, with published studies recommending that opportunities be created for students to grow, mature, and internalize their sense of professional identity over time. ${ }^{7,32}$ The teaching techniques ${ }^{22}$ employed in the delivery of the PIP have been reported to increase student autonomy by shifting focus from the instructor to the student ${ }^{33}$ and increasing students' motivation to learn. ${ }^{23,34}$ Students felt more self-determined and competent when teachers listened to their perspectives, encouraged conversation, and provided opportunities for students to work independently. ${ }^{19,22}$ Autonomy-supportive teaching has also been associated with higher rates of retention and greater perceptions of student competence. ${ }^{35}$

The significant increase in Pharm-S scores indicated that the motivation regulators (extrinsic or intrinsic) underpinning identity formation had changed over time to become more intrinsic in nature, presumably as a result of participation in the PIP increasing students' competence, relatedness, and autonomy. Both extrinsic and intrinsic motivation types are associated with increased levels of autonomy, with the latter representing the highest levels of autonomy or self-direction. A shift from extrinsic to intrinsic motivation

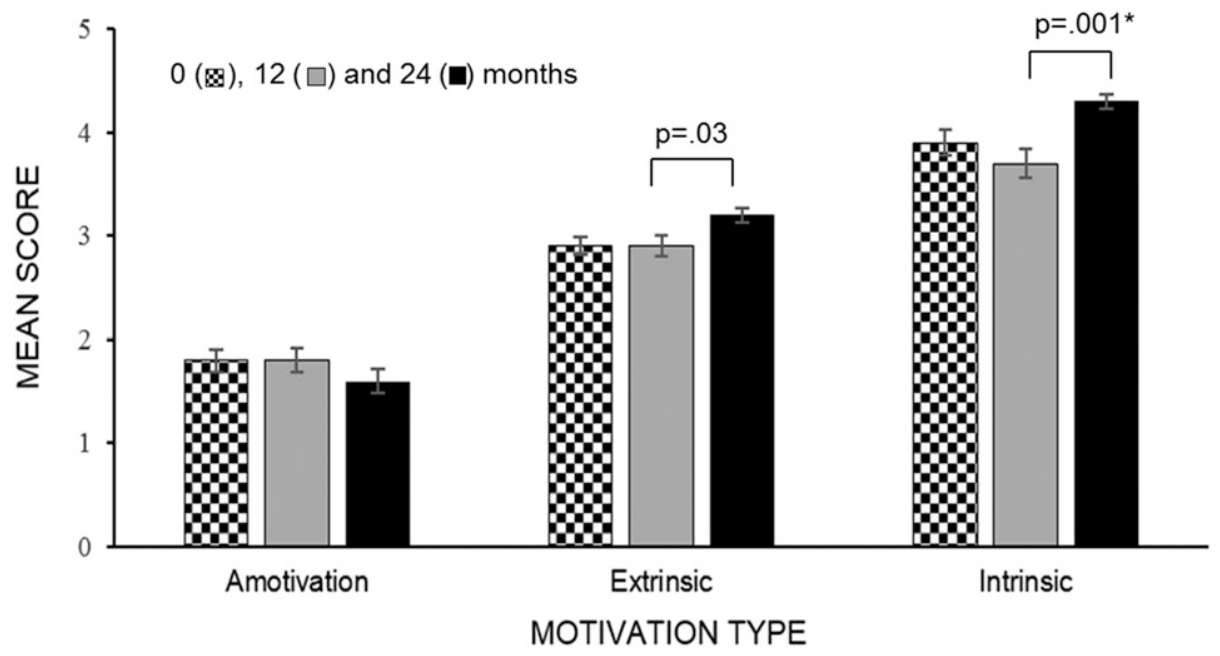

Figure 2. Pharm-S Motivation Type Scores (Mean,SE) of First Year Pharmacy Students in a Professional Identity Program over 24 Months. (*Significance level $<.05$ ) 


\section{American Journal of Pharmaceutical Education 2019; 83 (6) Article 6842.}

represents a move from externally controlling factors such as money or parental expectations to personal satisfaction, interest and enjoyment. ${ }^{19}$ With a continued focus on supporting student competence, relatedness, and autonomy, the trend could be expected to continue. It is this change in motivation types which also triggers the process of internalisation, resulting in identity formation.

Luyckx and colleagues have reported evidence of positive associations between basic psychological needs satisfaction and identity development in high school and college students. ${ }^{21}$ With such support, students are more likely to exhibit autonomous or self-determined behaviors, with the intrinsically motivated individual exhibiting the highest state of autonomy. This individual is motivated by enjoyment, satisfaction, and an inherent interest in the activity. ${ }^{19}$

Orsini and colleagues ${ }^{36}$ have also identified the importance of an autonomy-supportive approach in clinical teaching with benefits for professional practice. The authors explained that this technique represents a "humancentered" approach to teaching that equips students with the skills to offer autonomy-support to patients, thus improving healthcare delivery. ${ }^{23}$ This is because students who are taught in an autonomy-supportive manner become practitioners who are better positioned to provide care that facilitates patient autonomy. ${ }^{19}$ This is achieved through valuing patient perspectives, providing information, offering choice, and encouraging self-direction, ${ }^{19,23}$ which lead to better health behaviors and subsequent improved health outcomes for patients. ${ }^{19,37}$ This is extremely relevant for pharmacists adopting patient-centered practices and striving to improve medication adherence, which delivers better health outcomes. ${ }^{19}$

There are some limitations to the present study. First, data collection was carried out in a single pharmacy program, which limited the available sample size. The design of the PIP is such that it could be integrated into pharmacy programs in other schools and colleges, thereby there is opportunity for future research studying the impact of the PIP on larger samples sizes and a more diverse student population. Second, the data collection instruments relied on self-report measures; however, this is seen as the most appropriate approach in personal identity research. ${ }^{21}$ Finally, the main investigator had an instructor role within the program, which may have influenced students' responses. However, students were advised that the objective of the study was to ascertain their opinions and perspectives regarding the professional identity program only.

\section{CONCLUSION}

This novel professional identity program for pharmacy students represents a theory-based approach to early professional identity development. Pedagogical approaches, informed by SDT principles, focus on providing support for the development of student competence, relatedness, and autonomy. The program, commencing in first year and using autonomy-supportive teaching techniques, presents an early foundation for professional identity development. After two years of participation in the PIP, a validated SDT-based survey instrument detected an increase in levels of autonomy in participating students. Supporting student autonomy has the potential to better equip students with the ability to provide autonomy-support for patients, thus leading to improved health outcomes. The study supports the early implementation of professional identity development strategies as being essential to allow for adequate development and maturation of pharmacy students in preparation for successful transition to the professional workplace.

\section{REFERENCES}

1. Accreditation Council for Pharmacy Education. Accreditation Standards and Key Elements for the Professional Program in Pharmacy Leading to the Doctor of Pharmacy Degree ("Standards 2016"). https://acpe-accredit.org/pdf/Standards2016FINAL.pdf. Published 2015. Accessed August 9, 2017.

2. Cruess RL, Cruess SR, Boudreau JD, Snell L, Steinert Y. Reframing medical education to support professional identity formation. Acad Med. 2014;89(11):1446-1451.

3. AACP Task Force on Professionalism. Report of the AACP Professionalism Task Force. https://manualzz.com/doc/35669282/ cod-taskforce-on-professional-identity-formation-final-re. Published May 2014. Accessed July 19, 2019.

4. Jarvis-Selinger S, Pratt DD, Regehr G. Competency is not enough: integrating identity formation into the medical education discourse. Acad Med. 2012;87(9):1185-1190.

5. Skorikov VB, Vondracek FW. Occupational identity. In: Schwartz SJ, Luyckx K, Vignoles VL, eds. Handbook of Identity Theory and Research. New York: Springer; 2011:693-714.

6. Hammer DP, Berger BA, Beardsley RS, Easton MR. Student professionalism. Am J Pharm Educ. 2003;67(3):Article 96.

7. Schafheutle E, Hassell K, Ashcroft DM, Hall J, Harrison S. How do pharmacy students learn professionalism? Int J Pharm Pract. 2012;20(2):118-128.

8. Bridges SJ. Professional identity development: learning and journeying together. Research in Social and Admin Pharm. https:// doi.org/10.1016/j.sapharm.2017.03.054. Published 2017.

9. Dall'Alba G. Learning to Be Professionals. Vol 4. Dordrecht: Springer; 2009.

10. Johnson JL, Chauvin S. Professional identity formation in an advanced pharmacy practice experience emphasizing self-authorship. Am J Pharm Educ. 2016;80(10):Article 172.

11. Noble C, O'Brien M, Coombes I, Shaw PN, Nissen L, Clavarino A. Becoming a pharmacist: students' perceptions of their curricular experience and professional identity formation. Curr in Pharm Teach and Learn. 2014;6(3):327-339.

12. Goldie J. The formation of professional identity in medical students: considerations for educators. Med Teach. 2012;34(9):e641-648.

13. Crigger N, Godfrey N. From the inside out: a new approach to teaching professional identity formation and professional ethics. $J$ Prof Nurs. 2014;30(5):376-382. 


\section{American Journal of Pharmaceutical Education 2019; 83 (6) Article 6842.}

14. Van Huyssteen M, Bheekie A. The meaning of being a pharmacist: considering the professional identity development of first-year pharmacy students. African J of Health Prof Educ. 2015;7(2):208-211.

15. Adams RS, Daly SR, Mann LM, Dall'Alba G. Being a professional: three lenses into design thinking, acting, and being. Design Stud. 2011;32(6):588-607.

16. Trede F, Macklin R, Bridges D. Professional identity development: a review of the higher education literature. Stud High Educ. 2012;37(3):365-384.

17. Mylrea M, Sen Gupta T, Glass B. Developing professional identity in undergraduate pharmacy students: a role for selfdetermination theory. Pharmacy. 2017;5(2):16.

18. Deci E, Ryan R. Intrinsic Motivation and Self-Determination in Human Behaviour. New York: Plenum; 1985.

19. Deci E, Ryan, R. Handbook of Self-Determination Research. Rochester, NY: University of Rochester Press; 2002.

20. La Guardia J. Developing who I am: a self-determination theory approach to the establishment of healthy identities. Educa Psych. 2009;44(2):90-104.

21. Luyckx K, Vansteenkiste M, Goossens L, Duriez B. Basic need satisfaction and identity formation: bridging self-determination theory and process-oriented identity research. J Couns Psychol. 2009;56(2):276-288

22. Kusurkar RA, Croiset G, Ten Cate TJ. Twelve tips to stimulate intrinsic motivation in students through autonomy-supportive classroom teaching derived from self-determination theory. Med Teach. 2011;33(12):978-982.

23. Orsini C, Evans P, Jerez O. How to encourage intrinsic motivation in the clinical teaching environment: a systematic review from the self-determination theory. J Educ Eval Health Prof. $2015 ; 12(8)$.

24. Elvey R, Hassell K, Hall J. Who do you think you are? Pharmacists' perceptions of their professional identity. Int $J$ Pharm Pract. 2013;21(5):322-332.

25. Wallman A, Lindblad ÅK, Gustavsson M, Ring L. Factors associated with reflection among students after an advanced pharmacy practice experience (APPE) in Sweden. Am J Pharm Educ. 2009;73(6):Article 107.
26. Kinsella EA. The art of reflective practice in health and social care: reflections on the legacy of Donald Schön. Reflective Practice. 2010;11(4):565-575.

27. Sharpless J, Baldwin N, Cook R, et al. The becoming: students' reflections on the process of professional identity formation in medical education. Acad Med. 2015;90(6):713-717.

28. Worthington M, Salamonson Y, Weaver R, Cleary M. Predictive validity of the Macleod Clark professional identity scale for undergraduate nursing students. Nurse Educ Today. 2012;33(3):187-191.

29. Mylrea MF, Sen Gupta T, Glass BD. Validation of a motivation survey tool for pharmacy students: exploring a link to professional identity development. Curr in Pharm Teach and Learn. http://dx.doi.org/ 10.1016/j.cptl.2017.05.014. Published 2017. Accessed January 23, 2018.

30. Wilson PM, Sabiston CM, Mack DE, Blanchard CM. On the nature and function of scoring protocols used in exercise motivation research: an empirical study of the behavioral regulation in exercise questionnaire. Psychol Sport Exerc. 2012;13(5):614-622.

31. Adams K, Hean S, Sturgis P, Macleod Clark J. Investigating the factors influencing professional identity of first-year health and social care students. Learn in Health and Soc Care. 2006;5(2):55-68.

32. Taylor KM, Harding G. The pharmacy degree: the student experience of professional training. Pharm Educ. 2007;7(1):83-88. 33. Ten Cate TJ, Kusurkar RA, Williams GC. How self-determination theory can assist our understanding of the teaching and learning processes in medical education. AMEE guide No. 59. Med Teach. 2011;33(12): 961-973.

34. Niemiec CP, Ryan RM. Autonomy, competence, and relatedness in the classroom: applying self-determination theory to educational practice. Theory and Res in Educ. 2009;7(2):133-144.

35. Vallerand RJ, Fortier MS, Guay F. Self-determination and persistence in a real-life setting: toward a motivational model of high school dropout. J Pers Soc Psychol. 1997;72(5):1161-1176.

36. Orsini C, Evans P, Binnie V, Ledezma P, Fuentes F. Encouraging intrinsic motivation in the clinical setting: teachers' perspectives from the self-determination theory. Eur J Dent Educ. 2016;20(2):102-111. 37. Williams GC, Saizow RB, Ryan RM. The importance of selfdetermination theory for medical education. Acad Med. 1999;74(9): 992-995. 